\title{
The Shortcomings of Segment Reporting and their Impact on Analysts' Earnings Forecasts
}

\author{
5 November 2019
}

\begin{abstract}
In this paper, we deliver US-sample based evidence suggesting that segment reporting under the "management approach" of ASC 280 (SFAS 131) biases analysts' earnings per share (EPS) forecasts. We show that the error in EPS forecasts corresponds to a profitability "gap" between profitability aggregated from segment reporting and profitability computed from consolidated financial statements. We show that the forecast error is associated with the profitability gap when reported segments lack major profitability components such as assets, revenue, or operating income. Furthermore, we find that the EPS forecast error increases with an increased segment split when controlling for diversification, suggesting that disaggregation per se does not improve the ability of equity analysts to forecast earnings. Our panel consists of a sample of 591 US listed companies and covers the period 2009 to 2016 .
\end{abstract}

JEL classification: M41, M10, M21, G32.

Keywords: ASC 280 (SFAS 131), IFRS 8, Forecast accuracy, Segment reporting.

We gratefully acknowledge the workshop participants at the 2018 EAA Conference, 2017 ACA Research Symposium, the 2017 and 2018 Finance and Economics Seminar at the University of St.Gallen for their helpful comments and suggestions. We particularly thank Karl Frauendorfer, Markus Schmid and Stephen Zeff for their valuable inputs. 


\section{Introduction}

The necessity of understanding individual business activities and the importance of disaggregated information availability when analyzing companies and forecasting their earnings is long acknowledged and considered to be indispensable (Jenkins Committee, 1962, Association for Investment Management and Research (AIMR), 1993; American Institute of Certified Public Accountants (AICPA), 1994; Epstein and Palepu, 1999). In this respect, segment reporting complements information given in consolidated primary financial statements (balance sheet, income statement, and cash flow statement, equity statement). Without segment reporting, the consolidated financial statements, inherently, provide only limited information on individual business activities (Chen and Zhang, 2003). Accordingly, research documents that segment reporting provides new and useful information to analysts and investors, assists in forecasting earnings (Ettredge et al., 2005; Botosan et al., 2011) and potentially reduces information asymmetries (Kajüter and Nienhaus, 2017).

However, segment reporting may not be useful per se. There are reasonable concerns that segment reporting under the management approach warrants earnings management on segment level and impairs segment-reporting quality (European Securities and Markets Authority (ESMA), 2011). Indeed, under the current approach of segment reporting,

- the disclosed segment split (i.e., disaggregation of consolidated financial statement information to report individual business activities as segments),

- the granularity of reported line items per segment,

- the use of non-GAAP recognition and measurement principles for segment reporting, and

- the allocation of transactions (i.e., revenue, assets, operating income, etc.) to segments 
are highly discretionary. They provide management "leeway" to manage earnings on segment level (Wang and Ettredge, 2015; Berger and Hann, 2007; Givoly et al., 1999; Lail et al., 2014). Coupled with a lack of transparency regarding the actual criteria underlying management's segment reporting decisions, the management approach under ASC 280 (SFAS 131)-which is also adopted by IFRS 8-raises understandability and reliability concerns (e.g., ESMA, 2011; KPMG, 2010).

In this paper, we use the error in annual consensus EPS forecasts as a metric to analyze the usefulness of segment reporting for US-companies, which report segments according to ASC 280 (SFAS 131). We link the EPS forecast error to the "gap" between profitability aggregated from segments and the firms' consolidated profitability. Based on annual reporting data of 591 diversified US listed companies from 2009 to 2016, we find that segments, which lack key profitability components (i.e., revenue, assets, and/or operating income) yield a statistically significant EPS forecast error.

Our findings suggest that analysts neglect segments with incomplete data per segment (transaction allocation) in their EPS forecasts. Analysts seem to focus on those segments with a "full story" (i.e., with a complete set of profitability components per segment). In contrast to prior literature that finds that the non-GAAP measurement "gap" between segment and consolidated statements affects stock returns (Wang and Ettredge, 2015; Alfonso et al. 2012), we don't find a statistically significant effect of the use of non-GAAP measures for segment reporting on the accuracy of forecasted EPS. Furthermore, we provide evidence suggesting that an increased segment split (i.e., more information) is not associated with an increase in analyst forecast accuracy. On the contrary, an increased segment split is associated with lower forecast accuracy. This finding might result from the (poor) quality of the segment split disclosed by firms under the management approach, coupled with a trade-off between line item granularity and increases in the actual segment split. (Bugeja et al., 2015; Ettredge et al., 2006; Gotti, 2016). 


\section{Background, Literature and Hypotheses}

Diversified companies are a bundle of individual business activities with different risk, return and growth profiles (Krüger et al., 2015). Their assessment is inherently relevant for earnings forecasts and valuation analysis (Chen and Zhang, 2003, Botosan et al., 2011). Hence, unwinding individual business activities of diversified firms is vital for understanding the firm as whole and underlines the importance of disaggregated information availability. Therefore, information provided in segment reporting should ideally correspond to the individual business activities and their idiosyncratic characteristics (Herrmann and Thomas, 2000; Langdon, 1973; Collins, 1975). For example, analysts perceive segment reporting as more reliable when similar products, rather than dissimilar products are combined in a segment Maines et al., 1997).

\subsection{Segment reporting under $A S C 280$ and IFRS 8}

However, the discussion regarding how segment reporting should be designed-or even whether segment reporting should exist at all-is almost half a century old (Jenkins Committee, 1962) and still a topic of debate and improvement, PIR IFRS (2017). The current approach to segment reporting under ASC 280 (introduced in 1997) and IFRS 8 (introduced in 2006) is the management approach. It addresses the aforementioned idea of splitting primary financial statements into segments based on the managements' perspective on business activities. It aligns external with internal reporting for segments. Analyst favor this congruency of internal and external reporting, since they perceive it as more reliable than a segment reporting approach that differs from the firms' perspective on business activities (Maines et al., 1997; Botosan et al., 2011).

The management approach replaced the former risk-reward approach that required segments to be reported according to risk-reward profiles of a firm's 
individual business or geographical activities and required the reporting of specific line items that had to be consistent with accounting principles used to prepare the primary financial statements. The standard setters expected the management approach to deliver 'more' useful information when compared to the the risk-reward approach. By taking the perspective of the chief operating decision maker on business activities, the management approach is expected to disaggregate consolidated financial statement information based on the risk and rewards that the management thinks is important Nichols et al., 2013). Hence, the internal view of the management is expected to reflect the management's "fair" view on segment performance and segment-related risk (Wang and Ettredge, 2015).

However, the management approach indisputably gives the management leeway to manipulate earnings information at the segment level Wang and Ettredge, 2015). Research documents that firms shift income between reported segments with the aim of managing segment earnings (Berger and Hann, 2007; Lail et al., 2014). Since revenue and cost allocation requirements are tied to management's discretion and are lacking transparency, managers have incentives to overemphasize or hide segment profitability when agency or proprietary costs avoidance is high (Givoly et al., 1999; Botosan and Stanford, 2005).

We identify the segment split, the line item granularity, the recognition measurement of segment data, and the allocation of transactions to segments as the primary dimensions for the analysis of the quality of segment reporting. We therefore, briefly discuss these four dimensions and their implications on fundamental analysis and the EPS forecast error metric in order to develop our hypotheses.

\subsection{Segment Split}

The adoption of the management approach increased the number of reported business segments (Herrmann and Thomas, 2000: Street et al., 2000; 
Berger and Hann, 2003) and reduced single segment reporting (Botosan and Stanford, 2005). Intrinsically, an increased number of segments increases the available information. It enables diversified firms to report on different individual business activities. This corresponds to the idea of increasing the disclosure on business activities with different idiosyncratic risk-reward characteristic (Herrmann and Thomas, 2000). However, more segment information does not necessarily increase the information value of segment reporting. If understandability is limited, the analysis becomes less reliable (Maines et al., 1997) and analysts will primarily base their forecasts more on the consolidated financial statements which have stricter reporting requirements.

The segment split criteria-whether business activities have or have not been aggregated in segments-are seldom stated by companies in their reports and remain unclear (ESMA, 2011; KPMG, 2010). This lack of transparency is particularly striking, given that firms have full discretion over changing the segment split at any time if justified by the management's view on the business activities. Inconsistencies over time, but also between firms, restrain understandability and reliability of the segment split. Furthermore, there are no strict requirements to allocate (annual and/or quarterly) cost and revenue to segments on a consistent basis. In fact, quarterly segment reporting can deviate from annual segment reporting and must not add up to full year reporting numbers. Therefore, we hypothesize that:

H1: (After taking into account firm diversification) segment split is positively associated with EPS forecast error.

\subsection{Line item granularity}

Detailed financial statement data (fundamental signals) flow into the decision making process of market participants (Abarbanell and Bushee, 1997).

Profitability, growth and their drivers are linked to stock returns Akbas et al., 2017; Cooper et al., 2011; Nissim and Penman, 2001). Extant liter- 
ature emphasizes the importance of profitability metrics, such as operating profit margin and asset turnover and their development over time and crosssections for market participants in forecasting earnings and future profitability (Fairfield and Yohn, 2001; Soliman, 2008). Hence, in order to facilitate earnings forecasts and valuation tasks the availability of segment line items such as sales, costs and assets and their breakdown (i.e., nature of assets, costs, sales) is indispensable. If line item granularity is high and provided on segment level, it fundamentally assists in forecasting earnings and cash flows of individual business activities. It allows the assessment of overall firm fundamental risk and firm value.

However, line item disclosure is only required for key income statement items and only if the management actively uses these items in their decisionmaking process (SFAS 131.27, similarly IFRS 8.23), therefore putting segment line item reporting at the full discretion of the management.

In fact, firms appear to be resilient in providing a detailed line item breakdown of their business activities. Documenting the surfacing of a trade-off between line item disclosure and number of reported segments, studies find evidence of an actual reduction of line item disclosure when increasing the segment split following the implementation of the management approach (Bugeja et al., 2015; Ettredge et al., 2006, Gotti, 2016). In particular, key items such as assets per segment and capital expenditure per segment decrease while equity investments/income, income tax or interests expense/income marginally increase (Street et al., 2000; Herrmann and Thomas, 2000).

Furthermore, the reported segment line items do not provide the necessary depth needed to analyze the segment's value drivers. Key line items such as income tax expense, interest revenue, interest expense, R\&D expense, and similar, which would allow analysts to disentangle segment earnings into operating results, are only scarcely and selectively reported Herrmann and Thomas, 2000). Other critical items such as leases, financial assets, or op- 
erating liabilities against customers and suppliers (advance payments, or accounts payable) are not required to be reported separately for segments at all, and depend on the discretion of firms to report line items voluntarily.

Hence, line item granularity is helpful, if it is comprehensive and reconcilable. However, given the incomplete and discretionary character of line item reporting per segment and no requirement to reconcile segment line items to the line items in the consolidated statements, firms will provide increased discretionary (as opposed to mandatory) line item granularity in order to avoid agency or proprietary costs (Givoly et al., 1999; Botosan and Stanford, 2005). Ergo, the concept of line item reporting under the management approach potentially distorts the perception of the analyst. Consequently, we hypothesize that:

H2: Line item reporting is positively associated with EPS forecast error.

\subsection{Non-GAAP segment accounting}

Under the management approach, firms are allowed to use internal accounting principles for the recognition and measurement of line items (ASC 280-10-50-27, and similarly IFRS 8.25). However, non-GAAP measures may be difficult to interpret (e.g., IFRS 8, BC12). As a result, the recognition and measurement of segment line items might not add up to the earnings, the financial position or the cash flow presented in consolidated financial statements. The use of internal reporting policies for segment reporting creates indeed a gap and requires reconciliation. However, a full reconciliation that tracks segment data mismatches back to the individual line items of consolidated financial statements is not required. Under the current standard, a mere reconciliation of totals is deemed sufficient (ASC 280-10-50-30, 55-49).

Studies analyzing the aforementioned reconciliation gap find that segment reporting yields aggregated segment earnings in excess of consolidated earnings, a so-called negative gap (Wang and Ettredge, 2015; Alfonso et al., 2012). This suggests an incomplete allocation of expenses or losses to seg- 
ments. A negative gap exhibits a stronger association with stock returns, as opposed to a positive gap (i.e., consolidated earnings in excess of aggregated segment earnings); recurring and larger gaps are associated with high proprietary and agency costs and, moreover, the gaps are positively associated with surrogates of income items for which managers are unlikely to be held responsible (i.e., corporate intangibles, acquisition activity and special or unusual items) (Wang and Ettredge, 2015). Nevertheless, segment earnings appear to be incrementally useful to investors when measured against stock returns (Wang and Ettredge, 2015; Hollie and Yu, 2012). Neveretheless, the market appears to be mispricing the non-GAAP metrics, by not acknowledging the informational value of a full reconciliation (Hollie and $\mathrm{Yu}, 2012$ ), despite evidence suggesting that the gap is value-relevant (Alfonso et al., 2012).

It remains an open empirical question whether this gap is associated with an error in analyst forecast. Following the conceptual approach in the aforementioned studies, we calculate the gap between segment-based and consolidated statement-based "profitability gap" and analyze its association with the forecast error.

Profitability of core business activities, as a key metric for business analysis and valuation, e.g. (Nissim and Penman, 2001; Penman, 2016), it is an "anchor" for each valuation exercise. It helps forecasting future earnings of the firm if profitability metrics effectively reveal operating profitability of individual business activities. A key prerequisite for this task, however, is a disaggregation of business activities and a relevant line item reporting on segment level. A blurred picture of segment profitability is a setback that comes at the cost of a proper analysis of segment profitability and its usefulness in evaluating the firm's prospects. In fact, prior research also shows that the incremental information value of segment reporting is low and can be attributed to considerable measurement errors in reported segments Chen and Zhang, 2003; Givoly et al., 1999).

Given the level of discretion allotted to management by anchoring seg- 
ment reporting to the internal reporting practices, the low reconciliation requirements under ASC 280-10-50-30, 55-49 (and similarly IFRS 8.28, IG4), as well as a lack of transparency and understanding of segment data, we hypothesize that:

H3: A gap between profitability as obtained from consolidated primary financial statements and aggregated profitability as obtained from segment reporting is positively associated with the EPS forecast error.

\subsection{Allocation of transactions to segments}

Segment reporting might increase proprietary cost (i.e., managers conceal segments with relatively high abnormal profits to avoid harmful competition) or agency cost (i.e., managers hide segments with relatively low abnormal profits to protect their self-interest) of firms (Berger and Hann, 2007; Wang et al., 2011; Lail et al., 2014; Ettredge et al., 2006; Bugeja et al., 2015; Givoly et al., 1999). This incentivizes management not to accurately reveal segment profitability under the management approach, unless constrained to do so by dependance on external financing (Ettredge et al., 2006). Indeed, under the flexibility of the management approach, firms strategically report segment performance by shifting income between segments (Lail et al., 2014) and firms increased the number of segments under the management approach without revealing significantly more about differences in segment profitability (Ettredge et al., 2006).

In this sense, we introduce a profitability gap metric that aims at capturing the effect arising from segments for which key profitability items are missing. This metric enables us to investigate whether segments with an incomplete set of profitability items, have an effect on the observed forecast error. We calculate the profitability gap between segment reporting and the consolidated financial statements depending on missing profitability components for reported business segments. We hypothesize that

H4: The profitability gap arising from segments with missing profitability 
components (sales, assets, or/and operating income) is positively associated with the EPS forecast error.

\section{Research Design}

We test our hypotheses by running a set of regressions based on the model formalized under Equation 1:

$$
\begin{aligned}
\text { F_Error }_{i, t}= & \beta_{0}+\beta_{1} \text { SplitB }_{i, t}+\beta_{2} \operatorname{GranB}_{i, t}+\beta_{3} \operatorname{PrftGap} p_{i, t}+ \\
& +\Sigma \text { Controls }_{i, t}+\text { IndustryFE }+ \text { YearFE }+\xi_{i, t}
\end{aligned}
$$

Where, F_Error denotes the forecast error, SplitBS stands for our segment business segment split variable, $\operatorname{Gran} B S$ stands for the business segment line item granularity, PrftGap denotes the profitability gaps resulting from transaction allocation and non-GAAP accounting. Throughout all our different model specifications, we control for industry and year fixed effects, as well as include relevant control variables shown in prior literature to impact analysts' earnings forecast accuracy (Baldwin, 1984; Behn et al., 2008; Hope, 2003). All metrics are explained in the following and additional information is provided in the Appendix.

We calculate the forecast error at time $t$ as:

$$
F_{-} E_{R R O R}, t=\frac{\mid E P S_{i, t}-E P S \text { Forecast }_{i, t} \mid}{\text { Price }_{i, t}}
$$

To address our first hypothesis (H1), we investigate the cross-sectional effect of the reported segment split, SplitBS, on the forecast error. We measure the degree of business activity aggregation in reported segments at time $\mathrm{t}$ by constructing an Herfindahl-Hirschman index based metric with respect to segment business revenue (Berger and Hann, 2007; Kang et al., 2017). We calculate the index as the sum of the squared ratios of individ- 
ual segment revenue to total firm revenue. Since the Herfindahl-Hirschman index is a concentration metric, we calculate $\operatorname{Split} B S$ then as one minus the Herfindahl-Hirschman index to emphasize the effect of splitting financial information into segments:

$$
\operatorname{SplitBS}_{i, t}=1-\sum_{j}^{n}\left(\frac{\text { BusinessSegmentRevenue }_{i, j, t}}{\text { TotalRevenue }_{i, t}}\right)^{2}
$$

Where:

$n$ denotes the number of business segments of firm $i$ at time $t$.

By construction, this metric will range from 0 to below 1, whereby firms with an increased breakdown of business activities, the segment split, will score higher, while firms with a high degree of aggregation of business activities in few segments will score lower on the scale.

As mentioned in the previous section, we expect that the reported segment structure does not mirror actual firm diversification due to the discretionary segment split, income shifting between segments and internal management principles. We specifically control for diversification, in order to mitigate for the possibility that the effect captured by SplitBS on the $F \_E R R O R$ is in fact driven by actual firm diversification. Research suggests that more diversified firms have a higher segment split, reporting more segments (Kang et al., 2017). However, as a matter of this study, we think it makes sense to distinguish between segment split and diversification. The segment split is discretionary, mimicking managements perspective on the firms' activities. Thus, we control for diversification by counting the number of disclosed industry codes obtained from the first two digits of the reported NAICS codes and correspondingly include dummy variables throughout all our model specifications.

To address our second hypotheses (H2), we count the reported line items for each segment and then determine the number of line items each firm typically uses for the reporting of its segments. We conjecture that the 
most representative number of line items that a firm "typically" discloses is identified as the median number of the line items disclosed per segment for each firm in a given year. We then scale this number of line items for each firm by the highest such observed value on a yearly basis. The resulting metric, ranging from 0 to 1 , serves as a means of differentiating companies with various degrees of line item disclosure, with higher values signaling increased number of line items. We calculate this metric for mandatory line items according to ASC 280 (Compustat items: dps, esubs, ias, ivaeqs, nis, ops, revts) and for discretionary line items (all other Compustat items in the business segment data set with non-missing values) separately.

We approach our third hypotheses (H3) by computing the profitability gap as a result of non-GAAP accounting in segment reports. ROAGap1 is the "gap" between aggregated unlevered segment profitability and unlevered firm level profitability as obtained from the end of year financial statements. A similar approach can be found in Wang and Ettredge (2015), Alfonso et al. (2012), or Hollie and Yu (2012).

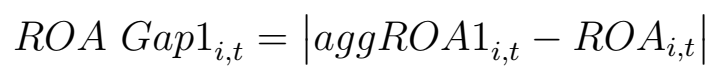

Where,

$$
\operatorname{aggROA} 1_{i, t}=\frac{\sum_{j}^{n} \text { Op.IncomeSegments }(\text { afterTax })_{i, j, t}}{\sum_{j}^{n} \text { SegmentAssets } s_{i, j, t}}
$$

And,

$$
R O A_{i, t}=\frac{\text { Op.Income }(\text { aftertax }) \text { ConsolidatedFin.Statements } s_{i, t}}{\text { TotalAssets }_{i, t}}
$$

With $i$ denotes the firm, $j$ the segment and $t$ the time period.

We also compute the profitability gap as a levered metric ROEGap1. 


$$
R O E G a p 1_{i, t}=\left|\operatorname{aggROE} 1_{i, t}-R O E_{i, t}\right|
$$

We reconstruct firm level return on equity from segment level return on assets as follows:

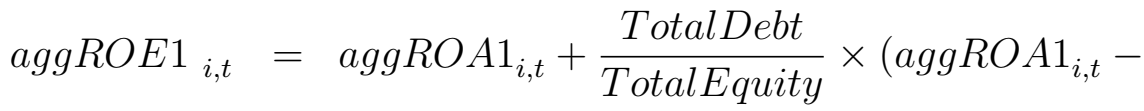

$$
\begin{aligned}
& - \text { NetBorrowing } \text { Costs }_{i, t} \text { ) }
\end{aligned}
$$

with $n$ representing the number of segments of firm $i$ at time $t$.

We use as a proxy for net borrowing costs (after taxes) the difference between operating income (before taxes) and net income (after tax) scaled by total debt:

$$
\text { NetBorrowingCosts }_{i, t}=\frac{\text { OpIncome }(\text { beforetaxes })_{i, t}-\text { NetIncome }_{i, t}}{\text { TotalDebt }_{i, t}}
$$

Return on equity on firm level is calculated by:

$$
R O E_{i, t}=\frac{\text { NetIncome }_{i, t}}{\text { TotalEquity }_{i, t}}
$$

For our fourth hypothesis (H4), we calculate ROAGap2, ROAGap3 as well as a levered version of the gaps: ROEGap2 and ROEGap3, similarly as before for ROEGap1. However, in the case of ROAGap2 we completely exclude all segment profitability components (segment operating income and segment assets) for those segments that do not report segment revenue or assets. When calculating ROAGap3 we completely excludes all segment profitability components (segment operating income and segment assets) for those segments that do not report segment revenue or assets or operating 
income. As a result, the difference between ROAGap2 and ROAGap3 stems from those segments which do not report segment assets yet report operating income. These particular cases are excluded from aggregated segment profitability when generating ROAGap3.

\subsection{Controls}

In line with accounting quality research, we control for earnings quality by including the accruals amount derived from the cash flow statement as a control variable in our regression model (Hribar and Collins, 2002). This is also in line with forecasting literature, which finds that analysts consistently take

into account discretionary accruals when issuing earnings forecasts (Givoly et al., 2011).

Analyst coverage is found to have a positive effect on earnings forecast accuracy (Huang et al., 2017). To account for this in our model, we control for the number of analysts' opinions that flow into the earnings forecast.

Volatile earnings are more difficult to forecast (Dichev and Tang, 2009). We calculate the 5-year earnings volatility for our sample and include it as an additional control in our models.

Larger firms are more likely to have increased press coverage and receive greater analyst attention (Kothari et al., 2009). We use total revenue as a proxy for firm size and control for it throughout our analysis.

We control for leverage, since research has shown that firms relying more heavily on external financing are willing to reveal more information about segment profitability differences (Ettredge et al., 2006).

All our models include firm parameters such as the ratio of accruals, number of analysts' estimates that contribute to the earnings forecast, the standard deviation of the past 5 years' earnings per share, while also controlling industry, year, diversification fixed effects and firm random effects. As a robustness check, we rerun our regressions controlling for firm fixed effects and find similar results. 


\section{Data}

Our initial dataset contains 4,411 US listed firms covering the 8-year period from 2009 to 2016 . We select 2009 as the starting year for our analysis, as it excludes the financial crisis, yet covers the period of internationally harmonized segment reporting (ASC 280 was adopted in substance by IFRS 8).

Due to the nature of our research question, we restrict our analysis to firms reporting two or more business segments. We also eliminate firms with only 1 geographical segment and for those segments for which the segment type specification is missing. Furthermore, we eliminate firms with missing data, negative book value of equity (since our analysis bases on calculations of also levered profitability gap) and outliers (when the forecast error is greater than $800 \%$ ). We drop firms which trade at a price below 1 USD, for which no earnings forecast is available, those for which we cannot calculate the past 5 year's earnings standard deviation, as well as those for which no segment level data exists (Akbas et al., 2017). The breakdown of our sample selection procedure and the corresponding firm count is presented in Table 1 .

Our final sample consists of 591 firms whith 2,786 firm-year observations. To alleviate the survivorship bias, we do not require firms to have observations in all years, resulting in an unbalanced panel.

\section{Empirical Results}

\subsection{Descriptive Statistics and Univariate Analysis}

Table 2 reports the descriptive statistics for our working sample. We report the correlation matrix in Tables $3 \mathrm{a}$ and $3 \mathrm{~b}$. For a complete description of our variables and data sources please refer to Table 9 in the Appendix.

Forecast Error (denoted as delta earnings-to-price ratio): The mean (median) absolute forecast error $F_{-} E R R O R$ scaled by price at time $t$ 
Table 1: This table shows, step-by-step, our sample selection process. Our final sample consists of 591 firms and covers 2,786 firm-year observations. To alleviate the survivorship bias, we do not require firms to have observations for all years, therefore yielding an unbalanced panel

\begin{aligned} & \hline 4,411 - U.S.-listed firms (Compustat) - Initial Sample \\ & \hline 1,918 - after dropping firms with less than 2 business segments \\ & 1,141 - after dropping firms with less than 2 geographical segments \\ & 1,137 - after dropping firms with missing type of segments \\ & 1,025 - after dropping penny stocks \\ & 1,007 - after dropping firms with negative book value \\ & 901 - after dropping outliers in terms of forecast error (F Error $>8) \\ & 894$ - after dropping firms for which no analyst coverage exists \\ & 892 - after dropping firms which do not have 5-yr earnings history \\ & 885 - after dropping firms with missing accruals \\ & 606 - after dropping firms with no segment profitability metrics \\ & 598 - after dropping firms for which no total debt is disclosed \\ & 591 - after dropping extreme ROE values (ROE $>500 \%) \\ &$\hline 591 - Working Sample $(2,786$ Firm - Years) \\ & \hline\end{aligned}


Table 2: This table presents descriptive statistics referring to our final sample of 591 firms. A breakdown showing descriptive statistics for each variable on a year by year basis is available in Table 8 in the Appendix.

\begin{tabular}{lrrrrrr}
\hline & $\mathrm{n}$ & \multicolumn{1}{c}{$\mathrm{m}$} & \multicolumn{1}{c}{$\mathrm{sd}$} & \multicolumn{1}{c}{$\mathrm{p} 25$} & $\mathrm{p} 50$ & $\mathrm{p} 75$ \\
\hline F ERROR & 2,790 & 0.051 & 0.132 & 0.007 & 0.019 & 0.044 \\
F ERROR (Sign) & 2,790 & -0.033 & 0.138 & -0.035 & -0.009 & 0.003 \\
ROA Gap1 & 2,790 & 0.035 & 0.176 & 0.001 & 0.006 & 0.021 \\
ROA Gap2 & 2,790 & 0.049 & 0.086 & 0.009 & 0.027 & 0.058 \\
ROA Gap3 & 2,790 & 0.031 & 0.059 & 0.006 & 0.017 & 0.036 \\
ROA Gap1 (Sign) & 2,790 & -0.019 & 0.178 & -0.009 & 0.000 & 0.004 \\
ROA Gap2 (Sign) & 2,790 & -0.037 & 0.092 & -0.053 & -0.022 & 0.000 \\
ROA Gap3 (Sign) & 2,790 & -0.020 & 0.063 & -0.031 & -0.013 & 0.000 \\
ROE Gap1 & 2,541 & 0.046 & 0.102 & 0.017 & 0.029 & 0.047 \\
ROE Gap2 & 2,541 & 0.035 & 0.047 & 0.012 & 0.024 & 0.043 \\
ROE Gap3 & 2,541 & 0.037 & 0.066 & 0.011 & 0.023 & 0.044 \\
ROE Gap1 (Sign) & 2,541 & 0.058 & 0.391 & 0.023 & 0.057 & 0.109 \\
ROE Gap2 (Sign) & 2,541 & 0.059 & 0.233 & -0.003 & 0.039 & 0.091 \\
ROE Gap3 (Sign) & 2,541 & 0.030 & 0.236 & -0.027 & 0.023 & 0.075 \\
SplitBS & 2,790 & 0.519 & 0.195 & 0.421 & 0.532 & 0.666 \\
SplitGS & 2,790 & 0.467 & 0.227 & 0.300 & 0.491 & 0.657 \\
GranBS_M & 2,790 & 0.725 & 0.152 & 0.571 & 0.857 & 0.857 \\
GranBS_D & 2,790 & 0.427 & 0.119 & 0.368 & 0.421 & 0.474 \\
GranGS_M & 2,790 & 0.364 & 0.183 & 0.167 & 0.417 & 0.500 \\
GranGS_D & 2,790 & 0.331 & 0.075 & 0.276 & 0.345 & 0.345 \\
ACCRUALS & 2,790 & 0.040 & 0.026 & 0.026 & 0.035 & 0.047 \\
NESTIMATES & 2,790 & 0.215 & 0.154 & 0.098 & 0.176 & 0.314 \\
EPS_STDEV & 2,790 & -0.080 & 1.174 & -0.841 & -0.170 & 0.519 \\
MARKET CAP & 2,790 & 8,315 & 23,338 & 757 & 2,082 & 5,676 \\
ASSETS & 2,790 & 9,491 & 39,627 & 764 & 2,255 & 5,957 \\
REVENUE & 2,790 & 7,263 & 18,161 & 744 & 1,960 & 5,012 \\
DEBT TO EQUITY & 2,790 & 0.835 & 1.587 & 0.180 & 0.481 & 0.880 \\
NSEGBUS & 2,790 & 4.318 & 1.669 & 3 & 4 & 5 \\
NSEGGEO & 2,790 & 4.767 & 3.496 & 3 & 4 & 6 \\
NNAICSBUS & 2,790 & 4.007 & 2.029 & 3 & 4 & 5 \\
NNAICSGEO & 2,790 & 1.853 & 0.399 & 2 & 2 & 2 \\
\hline & & & & & & \\
& & & & & \\
& & & &
\end{tabular}




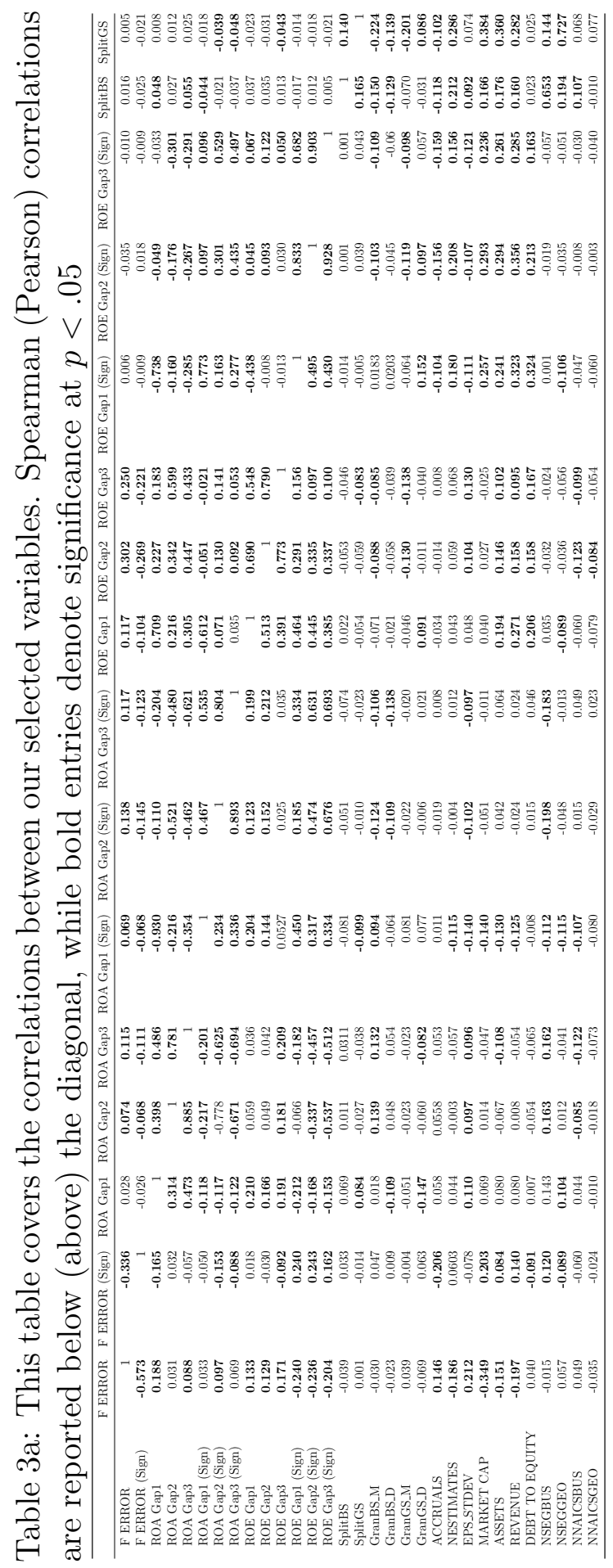




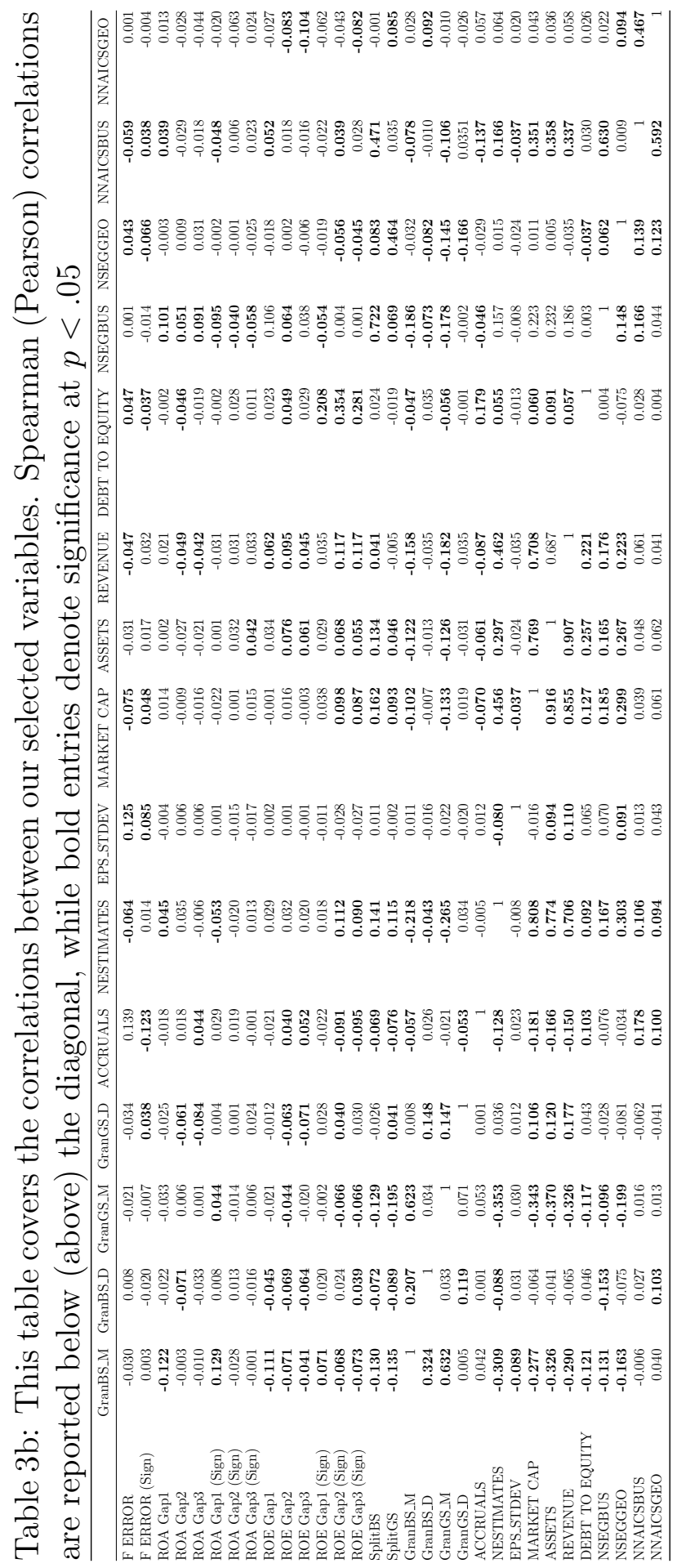


is 0.051 (0.019). If the sign of the forecast error is considered, the mean (median) value of the forecast error of the $F_{-} E R R O R($ Sign $)$ is $-0.033(-0.009)$. Table 4. Panel A splits and ranks the different profitability gap variables according to the forecast error quintiles. We observe that the higher quintiles of F_ERROR correspond to higher mean (median) profitability gaps, suggesting that EPS forecasts might indeed be influenced by segment reporting. However, the standard deviation of the profitability gaps is relatively high when the profitability gaps are split and ranked according the $F_{-} E R R O R$ and F_ERROR (Sign). We analyze this relationship further in a multivariate setting in Section 5.2.

Moreover, Table 4 Panel A reveals that the standard deviation of 0.132 (and similar 0.138 for F_ERROR(Sign) is primarily driven by the fifth quintile, which is the one with the largest forecast error. The negative values reported for the mean of F_ERROR(Sign) across quintiles one two and three indicate that a substantial proportion of the firms included in our sample exhibit overly optimistic earnings forecasts, whereby actual EPS figures undershoot analysts' expectations.

Profitability Gap (between aggregated profitability from segments and firm profitability): The mean (median) absolute unlevered profitability gaps ROAGap1, ROAGap2, ROAGap3 are reported at 0.035 (0.006), 0.049 (0.027), 0.031 (0.017). The mean (median) levered profitability gaps denoted by ROEGap 1, ROEGap 2 , ROEGap 3 are 0.046 (0.029), 0.035 (0.024), 0.037 (0.023). Considering also the direction (sign) of the gap, the mean (median) reported unlevered profitability gaps ROAGap1(Sign), ROAGap2(Sign), ROAGap3(Sign) and the mean (median) levered profitability gaps ROEGap1(Sign), ROEGap2(Sign), ROEGap3(Sign) are 0.019 (0.000), -0.037 (0.022), -0.020 (0.013) and 0.058 (0.057), 0.059 (0.039), 0.030 (0.023), respectively. These results provide initial evidence that the aggregated profitability from segments is higher than the profitability from the consolidated financial statements, which suggests that if analysts rely 
too much on segments reporting their EPS estimates might overestimate the profitability of assets, equity, as well as the firm's earnings. Again the standard deviation is high, further analysis is carried out in a multivariate setting (see section regression analysis).

Table 4, Panel B splits and ranks the unlevered profitability gap according to the forecast error when the sign of the forecast error $F_{-} E R R O R($ Sign) is also taken into account. The figures in the reported quintiles suggest that overly optimistic EPS estimates (depicting a negative sign) correspond to observations where segment aggregated profitability is indeed higher than consolidated profitability. Further evidence is also provided when considering the Spearman (Pearson) correlations reported in Table 3a. Specifically, the Spearman (Pearson) between the absolute forecast error F_ERROR and the levered (ROE) profitability gap metrics ROEGap1, ROEGap2, ROEGap3 is $0.133(0.117), 0.129(0.302)$ and $0.171(0.250)$, while if the sign is also taking into account, then the correlations are negative: -0.240 (0.006), -0.236 $(-0.035)$ and $-0.204(-0.010)$, respectively.

Segment Split: The mean (median) business segment split variable SplitBS is 0.519 (0.532), while geographical segment split variable Split $G S$ is $0.467(0.491)$.

Line Item Granularity: The mean (median) business segment granularity of mandatory $\operatorname{Gran}_{B} S_{-} M$ and discretionary line items $G r a n B S \_D$ are 0.725 (0.857) and 0.427 (0.421), respectively. The mean (median) geographical segment granularity covering mandatory $\operatorname{Gran}_{G} S_{-} M$ and discretionary line items GranGS_D are 0.364 (0.417) and 0.331 (0.345), respectively.

Number of segments and industries: The mean (median) number of business segments, denoted as NSEGBUS, is 4.318 (4.0) with a standard deviation of 1.669, while the mean (median) number of geographical segments, NSEGGEO, is 4.767 (4.0) with a standard deviation of 3.496. The mean (median) reported number of NAICS per company across business segments, denoted as NNAICSBUS, is 4.007 (4.0) with a standard deviation 


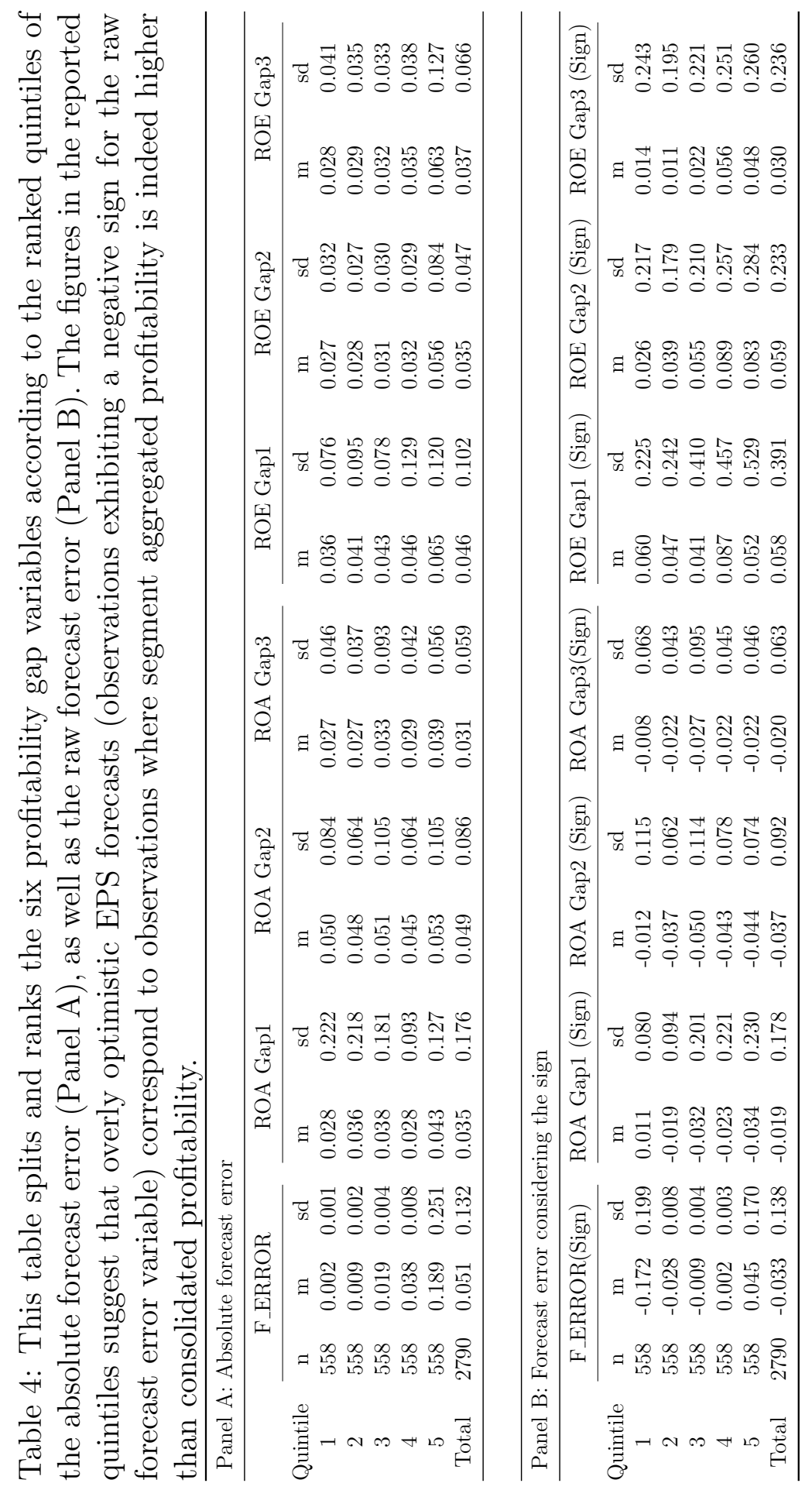


of 2.029, while in the case of geographical segments, NNAICSGEO, the mean (median) is 1.853 (2.0) with a standard deviation of 0.399 .

Table 5 Panel A splits and ranks the segment split variables: SplitBS, Split $G S$ and the line item granularity variables: $\operatorname{Gran} B S_{-} M, G r a n B S_{-} D$, Gran $G S_{-} M$, and $G r a n G S_{-} D$ according to the calculated forecast error quintiles of $F_{-} E R R O R$. Based on the correlation tables and contrary to the common expectation that an increased split would increase valuable information on business activities and facilitate the forecast of earnings, we find no apparent relationship between these metrics, at least base on this analysis. A possible explanation might be that the increased segment split is actually reflecting more diversified firms and offsets the information value of a greater segment split. However, the number of NAICS, NNAICSBUS, is quasi-constant throughout all quintiles, close to 4 , with only a slight decrease in the mean and standard deviation when considering the 5 quintiles of F_ERROR. Moreover, the correlation matrix does not suggest a strong association between diversification and the forecast error,while the correlation between the forecast error and the number of reported NAICS is negligibly low, as well as showing an inconclusive sign 0.049 (-0.059).

Segment split is often used as a proxy for (or confused with) diversification (e.g., Kang et al., 2017), despite the discretionary character of the actual segment split. To display the relationship between segment split, number of business segments and number of industries reported for business segments, Table 5, Panel B splits and ranks number of segments and the number of line items and NAICS against our segment split variable. Table 6 shows the number of number of NAICS for business segments and the number of segments and segment split for the corresponding firms. It reveals that a striking 71.4 percent of the firms operate in one, two, three or four industries but report, on average, in all cases only about the same number of segments and the same segment split. Moreover, in line with this argumentation, the increase in the average segment split from 0.209 to 0.538 , as depicted 


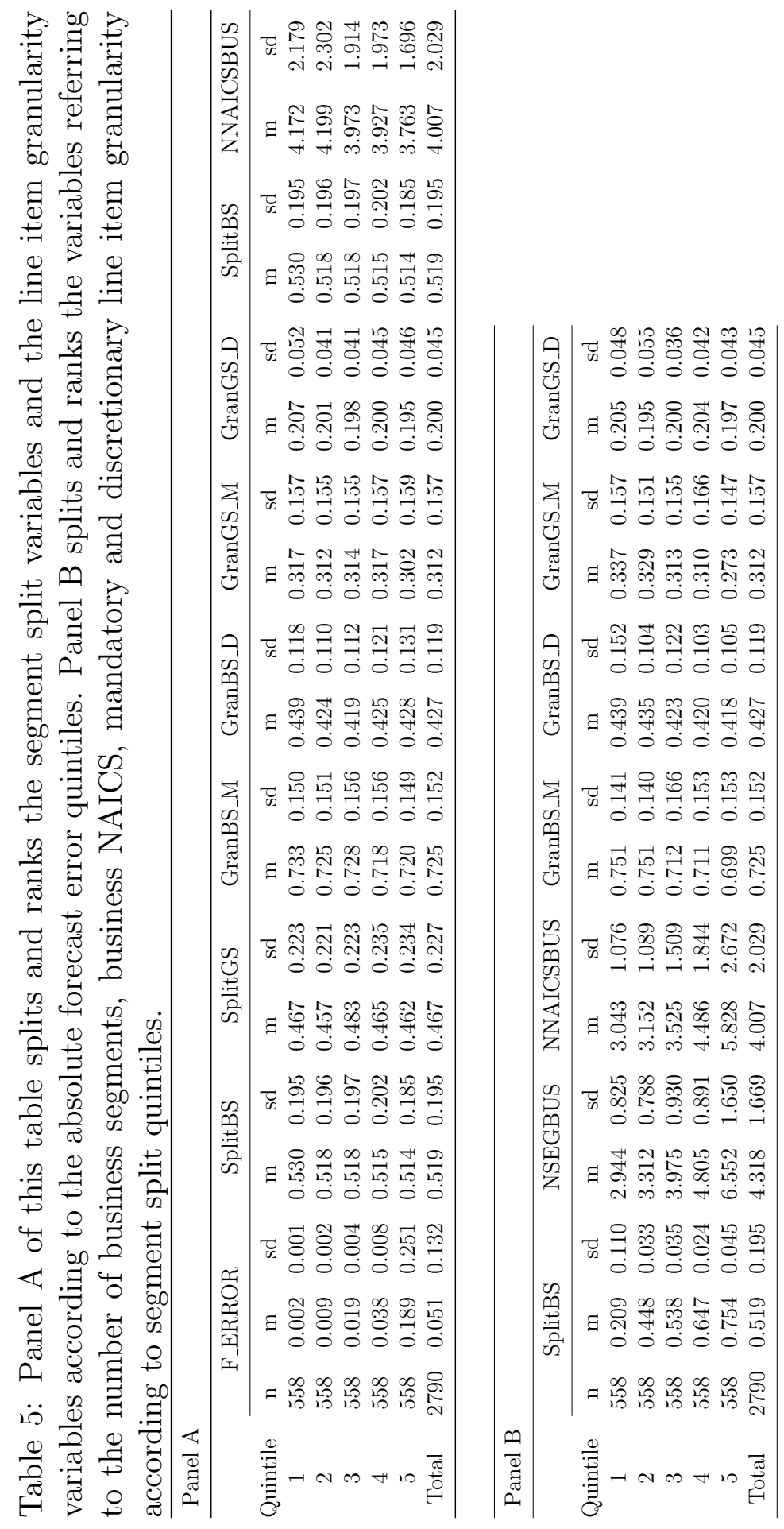


in Table5 in Panel B, referring to quintiles one to three (covering $60 \%$ of all firms) corresponds to firms having three to four business segments and reporting approximately three business NAICS.

Table 6: This table provides an overview of the number of business NAICS that firms in our data-set report and relates this number to the number of reported business segments and segment split.

\begin{tabular}{|c|c|c|c|c|c|c|c|}
\hline \multicolumn{4}{|c|}{ NNAICS BUS } & \multicolumn{2}{|c|}{ NSEGBUS } & \multicolumn{2}{|c|}{ SplitBS } \\
\hline Nr. & Firms & Perc. & Cum. & $\mathrm{m}$ & $\mathrm{sd}$ & $\mathrm{m}$ & $\mathrm{sd}$ \\
\hline 1 & 95 & 3.4 & 3.4 & 3.621 & 0.121 & 0.455 & 0.022 \\
\hline 2 & 480 & 17.2 & 20.6 & 3.567 & 0.060 & 0.435 & 0.008 \\
\hline 3 & 765 & 27.4 & 48.0 & 3.566 & 0.042 & 0.448 & 0.007 \\
\hline 4 & 653 & 23.4 & 71.4 & 4.044 & 0.050 & 0.499 & 0.007 \\
\hline 5 & 296 & 10.6 & 82.0 & 5.091 & 0.065 & 0.610 & 0.008 \\
\hline 6 & 185 & 6.6 & 88.7 & 5.627 & 0.105 & 0.659 & 0.009 \\
\hline 7 & 139 & 5.0 & 93.7 & 5.957 & 0.092 & 0.699 & 0.008 \\
\hline 8 & 78 & 2.8 & 96.5 & 5.705 & 0.141 & 0.681 & 0.009 \\
\hline 9 & 40 & 1.4 & 97.9 & 7.225 & 0.233 & 0.698 & 0.023 \\
\hline 10 & 27 & 1.0 & 98.9 & 7.481 & 0.386 & 0.767 & 0.010 \\
\hline 11 & 16 & 0.6 & 99.4 & 8.938 & 0.536 & 0.808 & 0.019 \\
\hline 12 & 5 & 0.2 & 99.6 & 8.800 & 0.200 & 0.833 & 0.020 \\
\hline 13 & 2 & 0.1 & 99.7 & 9.500 & 0.500 & 0.851 & 0.005 \\
\hline 14 & 2 & 0.1 & 99.8 & 10.500 & 0.500 & 0.854 & 0.010 \\
\hline 15 & 4 & 0.1 & 99.9 & 10.750 & 0.250 & 0.864 & 0.010 \\
\hline 16 & 1 & 0.0 & 99.9 & 9.000 & . & 0.819 & . \\
\hline 17 & 2 & 0.1 & 100.0 & 15.000 & 0.000 & 0.916 & 0.001 \\
\hline Total & 2790 & 100 & & 4.317 & 0.072 & 0.519 & 0.008 \\
\hline \multicolumn{4}{|c|}{ Sub Group of NNAICSBUS 1 to 4: } & 3.726 & 0.053 & 0.462 & 0.008 \\
\hline \multicolumn{4}{|c|}{ Sub Group of NNAICSBUS 5 to 17 : } & 5.794 & 0.119 & 0.662 & 0.010 \\
\hline
\end{tabular}

Furthermore, when looking at the relation between the forecast error and the number of business segments, we find similar results, namely a correlation of -0.015 (0.001). Given a mean (median) of business segments and NAICS of about 4 , the correlation between the segment split variable and the number 
of business segments is 0.653 (0.722); however, the correlation between the segment split and the number of NAICS is 0.107 (0.471), a substantially lower value by comparison, supporting our understanding that it is important to distinguish between segment split and diversification.

The analysis in Table 5. Panel B also provides evidence that an increased number of segments results in a decrease number of reported line items when the segment split increases, particularly for the quintiles 4 and 5 , which is in line with the finding in prior studies ( 2006: Gotti, 2016). Also, when looking at the correlation figures in Table 3a, the segment split, mandatory and discretionary line items are not linked to a reduction in the forecast error in this univariate setting $-0.039,-0.030,-0.023$ (0.016, -0.030, 0.008).

Size: The mean (median) size as measured thorugh market capitalization MARKET_CAP is 8,315 $(2,082)$ million USD with a standard deviation of 23,338, asset size ASSETS is 9,491 (2,255) million USD with a standard deviation of 39,627 and revenue REVENUE is $7,263(1,960)$ million USD with a standard deviation of 18,161 .

There is a slight negative correlation between the accounting quality variable $A C C R U A L S$ and the business segment split SplitBS of -0.118 (-0.069), whereby the higher the split, the lower the number of disclosed mandatory line items -0.150 (-.130). A similar picture is documented when looking at the negative correlation between the geographical segment split and mandatory line items granularity -.224 (-0.195), implying that an increased segment split is correlated with a reduction in line items (Bugeja et al., 2015, Ettredge et al., 2006, Gotti, 2016). Conversely, when looking at discretionary line items, the opposite can be observed.

Larger companies, as measured by market cap, total assets or revenue benefit from increased analyst coverage as evidenced by correlations between 0.706 and 0.808 (0.297 and 0.462).

The forecast error positively correlates with standard deviation of last 
five years of EPS 0.212 (0.125). In contrast to existing findings referring to the impact of leverage on information availability (Dhaliwal et al., 2011), the debt-to-equity ratio does not correlate with the forecast error 0.040 (0.047), nor with the segment split -0.039 (0.016) in this univariate setting.

\subsection{Regression Analysis}

Table 7 depicts the results of our regression analysis. Panel A and Panel B of Table 7 document and quantify the effect of the profitability gaps on the forecast error. All of the 4 regressions address the relationship between the profitability gap from "no-full-story" segments, i.e. segments that do not report revenue or assets: $R O A_{-} G a p 2, R O E_{-} G a p 2$, or segments lacking revenue, assets or operating income: ROA_Gap3 and ROE_Gap3 and its effect on the forecast error. We find and document a statistically significant (coefficient for the levered metric is 0.797 for $R O E_{-}$Gap2) positive association with the forecast error. This comes to support our fourth hypothesis (H4). This finding suggests that analysts' earnings forecasts are biased towards firm profitability as derived from segments, for which a complete set of profitability-related data items (assets, revenues or operating earnings) is disclosed. This finding is significantly tied to the amount and even the sign of the earnings forecast error-statistically and economically significant coefficients of PrftGap(positive), R-squared of 0.46, reported in Panel B of Table 7 .

This suggests that the attention of analysts might be directed to those segments where performance metrics are readily available. Findings are in line with prior research that shows that the discretion of segment reports and usefulness of actual segment data is exploited by management, suggesting that companies manage segment profitability through the allocation of business activities when aggregating them into reported segments (Berger and Hann, 2007) and inter-segment income shifting (Lail et al., 2014; You, 2014). 
Given the lack of a complete reconciliation requirement between aggregated segments and firm level reporting, as well as the leeway provided by the low reporting requirements, coupled with the internal measurement principle, we tested if the existence of a discrepancy between segment aggregated profitability and firm level profitability explains the forecast error $R O A_{-}$Gap 1 , $R O E_{-} G a p 1$. However, the evidence for a profitability gap that results from non-GAAP accounting (internal recognition and measurement principles for reported segments in contrast to the U.S.-GAAP for consolidated financial statements) is weak and only supports $\mathrm{H} 3$ in the case of the levered metric, ROE_Gap 1 . This could result from the firms' use of external accounting principles for their internal and segment reporting, facilitating the preparation of segment reporting and internal reports as it is readily available Crawford et al., 2012, Nichols et al., 2012).

Throughout all of our different model specifications we find statistically significant evidence that the segment split is positively associated with the forecast error. To make sure that the findings are not driven by the level of firm diversification, we control for firm diversification by creating dummies for the number of business NAICS of a firm. The finding directly supports our first hypothesis (H1) and strengthens the idea that an increased segment split under the loose and permissive regulatory framework in defining and aggregating business activities into reporting business segments does not serve as a catalyst for forecasting purposes.

Referring to the coefficients of $G r a n B S_{-} M$ and $\operatorname{Gran} B S_{-} D$, we find that increased mandatory line item granularity $(\mathrm{H} 2)$ is associated with a decrease in the forecast error, while increased discretionary disclosure is associated with increases in the forecast error. This finding provides further evidence suggesting that the leeway and discretion under the current standard might be impeding the work of outside analysts, yielding less accurate forecasts. 


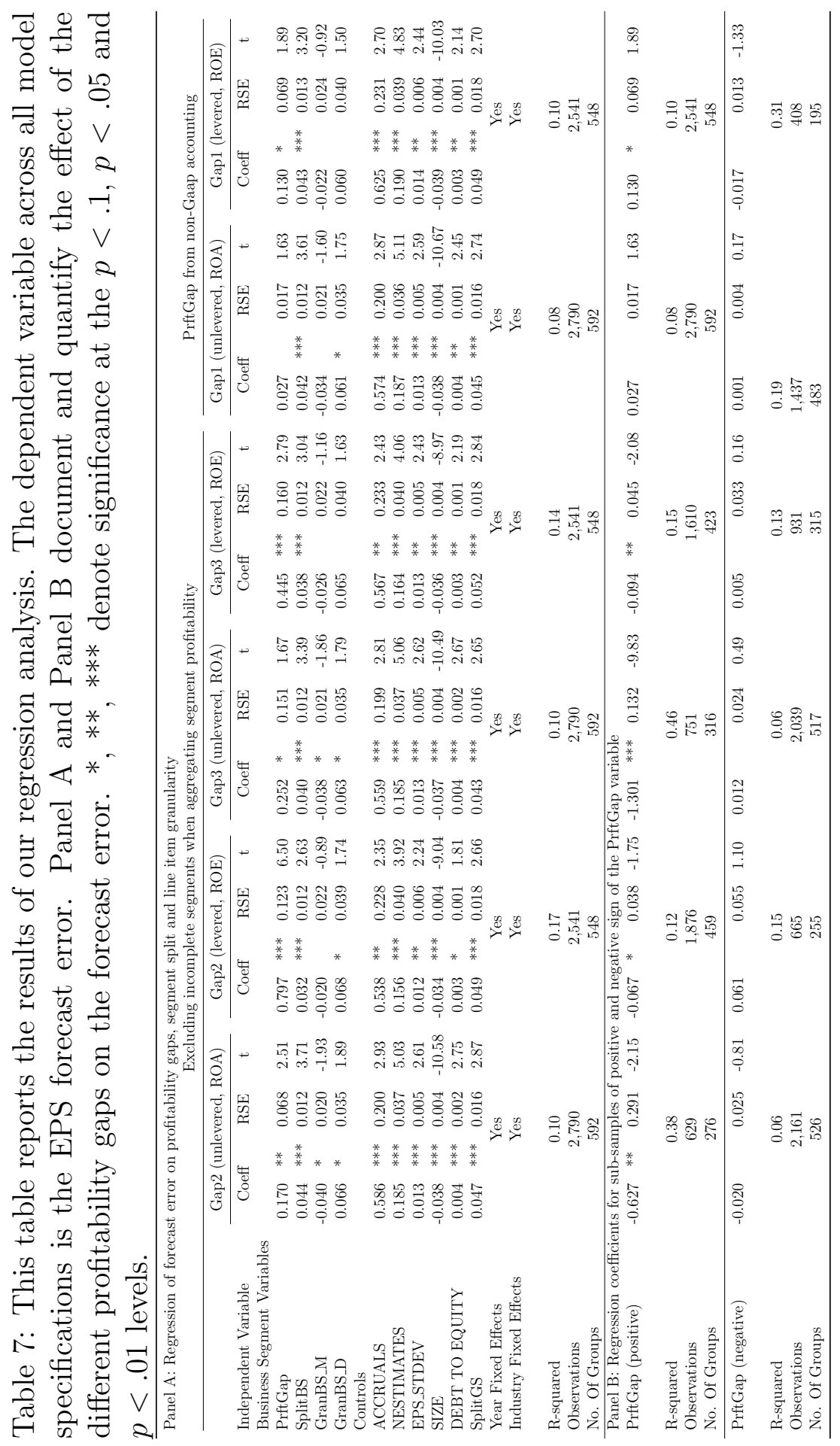




\section{Conclusion}

Indisputably, segment reporting is a powerful tool for the firm in its communication with analysts and investors. However, segment reporting provides valuable information if it reliably reveals current performance of major business activities. In so doing, it provides a benchmark for the future guidance of the firm's management and it assists analyst in their forecasts and investors in their investment decision-making. Poor segment reporting, in turn, bears the risk of misinforming analysts and investors.

In this study, we argue, that discretion with regard to the segment split, allocation and granularity of segment data, coupled with shortcomings in matching and reconciling segment data with data from primary financial statements, impedes an effective analysis of reported segments and hence the evaluation of the company's prospects. In particular, over-reliance by analysts on the (incomplete) data presented for segments bears the risk of resulting in a systematic forecast error, while the lack of key line items amplifies the discretionary nature of segment reporting.

Under ASC 280 (SFAS 131) and similarly IFRS 8, segment reporting aims at presenting financial information disaggregated into reporting segments, with the goal of enabling users to analyze individual business activities of the company and evaluate its prospects as a whole (ASC 280-10-1, IFRS 8.1). This is in line with research that suggests that disclosure on individual business activities (aggregated in segments) leads to an increased permeability of earnings forecasts into stock returns (Ettredge et al., 2005) and contributes to market efficiency in general (Hossain, 2008; Park, 2011).

With this study, we contribute to the existing segment reporting literature by investigating the usefulness of segment reporting with respect to EPS forecasting and EPS forecast accuracy. We address this question by a bottom up approach, aiming to reconcile firm level profitability by aggregating individual segment level profitability.

We provide evidence that there is a positive association between segment 
reporting profitability and earnings forecasts accuracy, which suggests that analysts might be biased in their earnings forecast. We document a statistically (and economically) significant relationship between the identified discrepancy and the forecast error, also when considering the sign of the error. We show the existence of a profitability gap between segment-aggregated profitability and (consolidated) firm level profitability and provide evidence that this gap is positively associated with the analysts' earnings per share forecast error. In particular, our findings suggest that the "full-story" segments drive the forecast error. Analysts will potentially use the segment data as input in their models to forecast segment and then firm profitability. However, in contrast to prior literature which finds that the non-GAAP measurement "gap" between segment and consolidated statements affects stock returns (Wang and Ettredge, 2015, Alfonso et al., 2012), we don't find a statistically significant effect of the use of non-GAAP measures for segment reporting on the accuracy of forecasted EPS.

Our findings suggest that analyst forecasts might be influenced by the firms' allocation and measurement of segment data, the reported line item granularity and segment split, which directs analyst attention primarily to those segments that allow for profitability calculations, leaving out segments, which do not report components of profitability metrics.

Moreover, we find that companies with less segments have a lower forecast error-after controlling for the level of firm diversification. Indeed, low segment split company forecasts are even more accurate when the discrepancy of segment and consolidated profitability is high, signaling that analysts might ignore segment data when a mismatch is obvious. Greater disaggregation across reported segments is not helping analysts in their exercise of forecasting earnings. This finding suggests that the split of firm level data into reported segment data does not correspond to individual business activities and their idiosyncratic risk characteristics and therefore systematically contributes to the analyst forecast error. It also suggests that granularity of 
line item disclosure and the leeway to shuffle relevant line item information between segments play a key role in the assessment of the firm's business activities.

Our findings are in line with previous research that finds that current segment reporting fails to provide an adequate split according to a diversified firm's individual business profitability, risk and growth dimensions. We attribute our findings to the reporting requirements of segment data under the "management approach". This includes (1) reporting financial data that is used for internal management purposes and that may not be fully or at all be in line with GAAP coupled with little to no reconciliation needs, (2) aggregation of business activities to reportable segments based on the management's internal view, and (3) aggregation and reallocation of assets, costs and sales if justified by internal reporting principles without any transparency or consistency requirements.

Discretionary disaggregation coupled with limited disclosure of key line items (such as a breakdown between operating and financial assets) do not facilitate an accurate understanding, i.e. a breakdown of current profitability into its core drivers, which in turn would serve as a basis for forecasting future profitability. Furthermore, the discretionary character of segment reports is amplified by the fact that reported segment data under both standards, US-GAAP and IFRS, is neither required to match with data provided in primary financial statements, nor is a full reconciliation required that tracks segment data mismatches back on the line item of financial statements. As a result, segment reporting lacks important information that is necessary for profitability analysis and forecasting. Nevertheless, the analyst's exercise of analyzing segment profitability to understand a company's risk, return and growth characteristics with the ultimate aim of forecasting sustainable future earnings requires a clear view on core profitability metrics from the business activities and their development, as well as an understanding of the underlying accounting. 
We interpret our results as triggering evidence for the fact that the statusquo of segment reporting falls short of disclosing vital information, which is relevant for analysts in their forecasting of future earnings. Surpassed in terms of disclosure amount and scope by end of year reporting, which offers a relatively good basis for assessing profitability, growth and risk, segment reporting falls short of delivering the vital value added needed by analysts when forecasting future earnings. Consequently, we see that for firms whose consolidated end of year reported numbers, disclosed in the more detailed firm level reporting and therefore closely resembling those of the concentrated segment, forecast errors are lower. 


\section{References}

Abarbanell, J. S. and Bushee, B. J. (1997). Fundamental analysis, future earnings, and stock prices. Journal of Accounting Research, 35(1):1-24.

Akbas, F., Jiang, C., and Koch, P. D. (2017). The trend in firm profitability and the cross section of stock returns. The Accounting Review, 92(5).

Alfonso, E., Hollie, D., and Yu, S. (2012). Managers' segment financial reporting choice: An analysis of firms' segment reconciliations. The Journal of Applied Business Research, 28(6):1413-1441.

American Institute of Certified Public Accountants (AICPA) (1994). Improving business reporting - a customer focus. report of the aicpa special committee on financial reporting.

Association for Investment Management and Research (AIMR) (1993). Financial reporting in the 1990s and beyond. Charlottesville, Va.

Baldwin, B. A. (1984). Segment earnings disclosure and the ability of security analysts to forecast earnings per share. Accounting Review, 59(3):376-389.

Behn, B. K., Choi, J. H., and Kang, T. (2008). Audit quality and properties of analyst earnings forecasts. Journal of Accounting Research, 41(2):327-349.

Berger, P. G. and Hann, R. N. (2003). The impact of sfas no. 131 on information and monitoring. Journal of Accounting Research, 41(2):163-223.

Berger, P. G. and Hann, R. N. (2007). Segment profitability and the proprietary and agency costs of disclosure. The Accounting Review, 82(4):869906.

Botosan, C. A., McMahon, S., and Stanford, M. (2011). Representationally faithful disclosures, organizational design and managers' segment reporting decisions. 
Botosan, C. A. and Stanford, M. (2005). Managers' motives to withhold segment disclosures and the effect of sfas no. 131 on analysts' information environment. The Accounting Review, 80(3):751-771.

Bugeja, M., Czernkowski, R., and Moran, D. (2015). The impact of the management approach on segment reporting. Journal of Business Finance and Accounting, 42(3):310-366.

Chen, P. F. and Zhang, G. (2003). Heterogeneous investment opportunities in multiple-segment firms and the incremental value relevance of segment accounting data. The Accounting Review, 78(2):397-428.

Collins, D. W. (1975). Sec product line reporting and market efficiency. Journal of Financial Economics, 2:125-164.

Cooper, M. J., Gray, P., and Johnson, J. (2011). Asset growth and the crosssection of stock returns. Journal of Banking and Finance, 35(3):670-680.

Crawford, L., Extance, H., Hellier, C., and Power, D. (2012). Operating segments: The usefulness of ifrs. ICAS Insight, the Institute of Chartered Accountants.

Dhaliwal, D., Hogan, C., Trezevant, R., and Wilkins, M. (2011). Internal control disclosures, monitoring, and the cost of debt. The Accounting Review, 86(4):1131-1156.

Dichev, I. D. and Tang, V. W. (2009). Earnings volatility and earnings predictability. Journal of Accounting and Economics, 47(1):160-181.

Epstein, M. J. and Palepu, K. (1999). What financial analysts want. Strategic Finance, 80(10):48-52.

Ettredge, M. L., Kwon, S. Y., Smith, D. B., and Stone, M. S. (2006). The effect of sfas no. 131 on the cross-segment variability of profits reported by multiple segment firms. Review of Accounting Studies, 11(1):91-117. 
Ettredge, M. L., Kwon, S. Y., Smith, D. B., and Zarowin, P. A. (2005). The impact of sfas no. 131 business segment data on the market's ability to anticipate future earnings. The Accounting Review, 80(3):773-804.

European Securities and Markets Authority (ESMA) (2011). Review of european enforcers on the implementation of ifrs 8-operating segments.

Fairfield, P. M. and Yohn, T. L. (2001). Using asset turnover and profit margin. Review of Accounting Studies, pages 371-385.

Givoly, D., Hayn, C., and D'Souza, J. (1999). Measurement errors and information content of segment reporting. Review of Accounting Studies, $43(131): 15-43$.

Givoly, D., Hayn, C., and Yoder, T. (2011). Do analysts account for earnings management?

Gotti, G. (2016). Discussion of segment disclosure quantity and quality under ifrs 8: Determinants and the effect of financial analysts' earnings forecast errors. International Journal of Accounting, 51(4):462-463.

Herrmann, D. and Thomas, W. B. (2000). An analysis of segment disclosures under sfas no. 131 and sfas no. 14. Accounting Horizons, 14(3):287-302.

Hollie, D. and Yu, S. (2012). Do reconciliations of segment earnings affect stock prices? Journal of Applied Business Research, 28(5):1085-1106.

Hope, O. K. (2003). Disclosure practices, enforcement of accounting standards, and analysts' forecast accuracy: An international study. Journal of Accounting Research, 41(2):235-272.

Hossain, M. (2008). Change in value relevance of quarterly foreign sales data of u.s. multinational corporations after adopting sfas 131. Review of Quantitative Finance and Accounting, 30(1):1-23. 
Hribar, P. and Collins, D. W. (2002). Errors in estimating accruals: Implications for empirical research. Journal of Accounting Research, 40(1).

Huang, S. X., Pereira, R., and Wang, C. (2017). Analyst coverage and the likelihood of meeting or beating analyst earnings forecasts. Contemporary Accounting Research, 34(2):871-899.

Jenkins Committee (1962). Report of the company law committe.

Kajüter, P. and Nienhaus, M. (2017). The impact of ifrs 8 adoption on the usefulness of segment reports. Abacus, 53(1):133-157.

Kang, T., Khurana, I. K., and Wang, C. (2017). International diversification, sfas 131 and post-earnings-announcement drift. Contemporary Accounting Research, 43(4):2152-2178.

Kothari, S. P., Li, X., and Short, J. E. (2009). The effect of disclosures by management, analysts, and business press on cost of capital, return volatility, and analyst forecasts: A study using content analysis. The Accounting Review, 84(5):1639-1670.

Krüger, P., Landier, A., and Thesmar, D. (2015). The wacc fallacy: The real effects of using a unique discount rate. The Journal of Finance, $70(3): 1253-1285$.

Lail, B. E., Thomas, W. B., and Winterbotham, G. J. (2014). Classification shifting using the "corporate/other" segment. Accounting Horizons, 28(3):455-477.

Langdon, W. E. (1973). Extended financial reporting by diversified companies. Cost and Management, pages 50-53.

Maines, L., McDaniel, L., and Harris, M. (1997). Implications of proposed segment reporting standards for financial analysts' investment judgments. Journal of Accounting Research, 35:1-24. 
Nichols, N., Street, D. L., and Tarca, A. (2013). The impact of segment reporting under the ifrs 8 and sfas 131 management approach: A research review. Journal of International Financial Management 83 Accounting, 24(3):261-312.

Nichols, N. B., Street, D. L., and Cereola, S. (2012). An analysis of the impact of applying ifrs 8 on the segment disclosures of european blue chip companies. Journal of International Accounting Auditing and Taxation, 21(2):261-312.

Nissim, D. and Penman, S. H. (2001). Ratio analysis and equity valuation: From research to practice. Review of Accounting Studies, 6:109-154.

Park, J. C. (2011). The effect of sfas 131 on the stock market's ability to predict industry-wide and firm-specific components of future earnings. Accounting and Finance, 51(2):567-607.

Penman, S. (2016). The design of financial statements.

Soliman, M. T. (2008). The use of dupont analysis by market participants. The Accounting Review, 83(3):823-853.

Street, D. L., Nichols, N. B., and Gray, S. (2000). Segment disclosures under sfas no. 131: Has business segment reporting improved? Accounting Horizons, 14(3):259-285.

Wang, Q. and Ettredge, M. L. (2015). Discretionary allocation of corporate income to segments. Research in Accounting Regulation, 27:1-13.

Wang, Q., Ettredge, M. L., Huang, Y., and Sun, L. (2011). Strategic revelation of differences in segment earnings growth. Journal of Accounting and Public Policy, 30(4):383-392.

You, H. (2014). Valuation-driven profit transfer among corporate segments. Review of Accounting Studies, 19(2):805-838. 
Appendix 


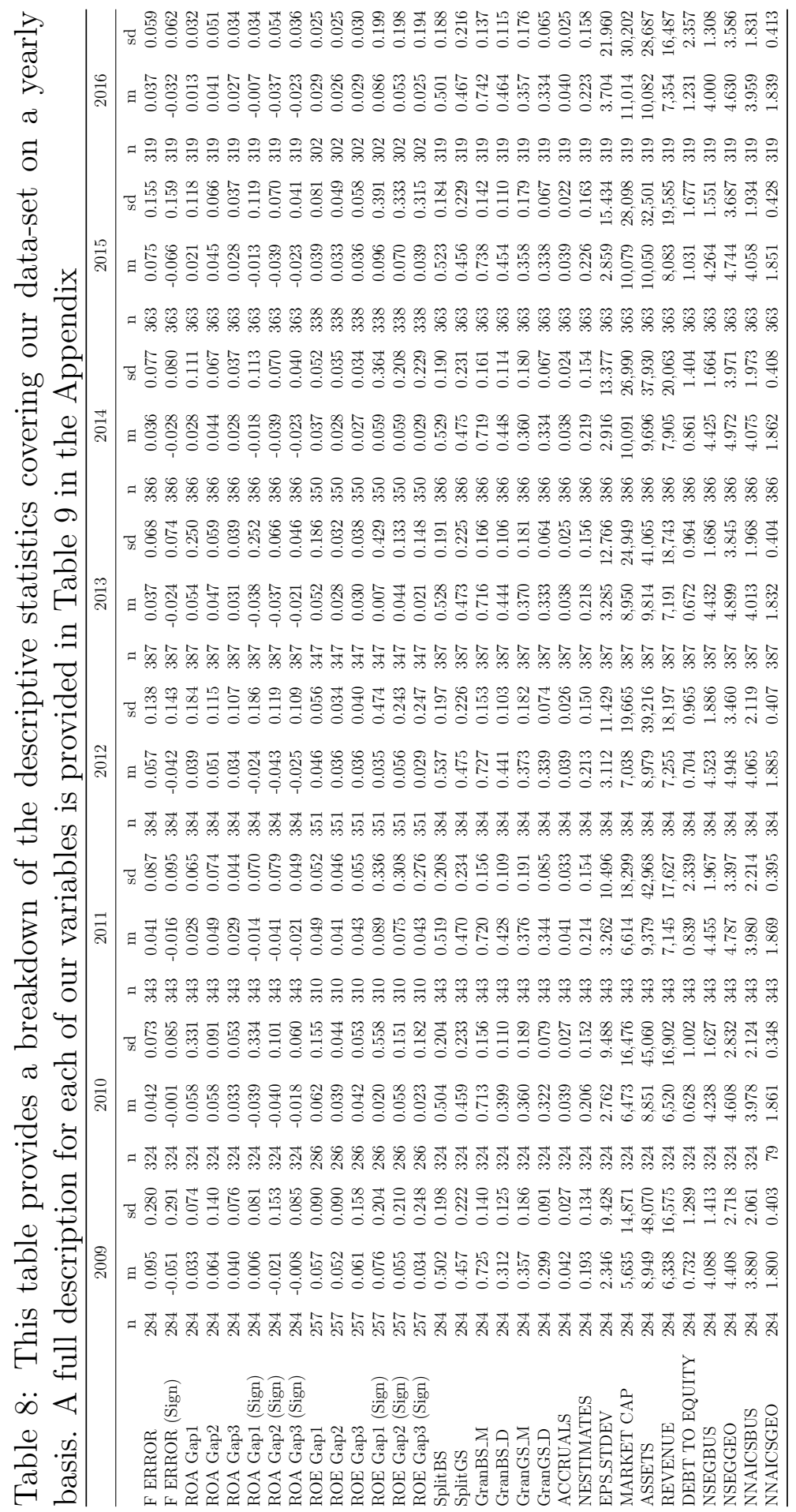




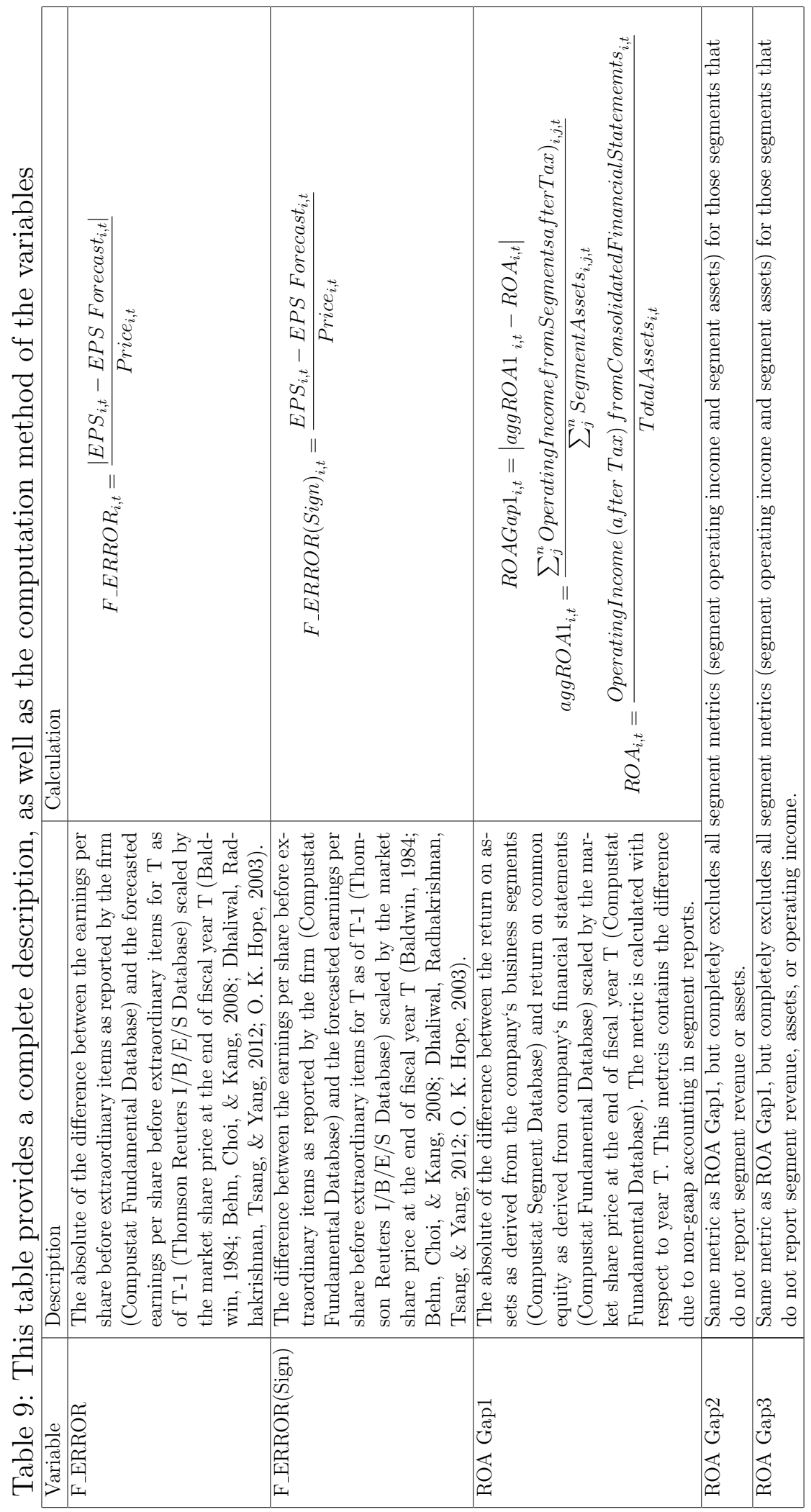




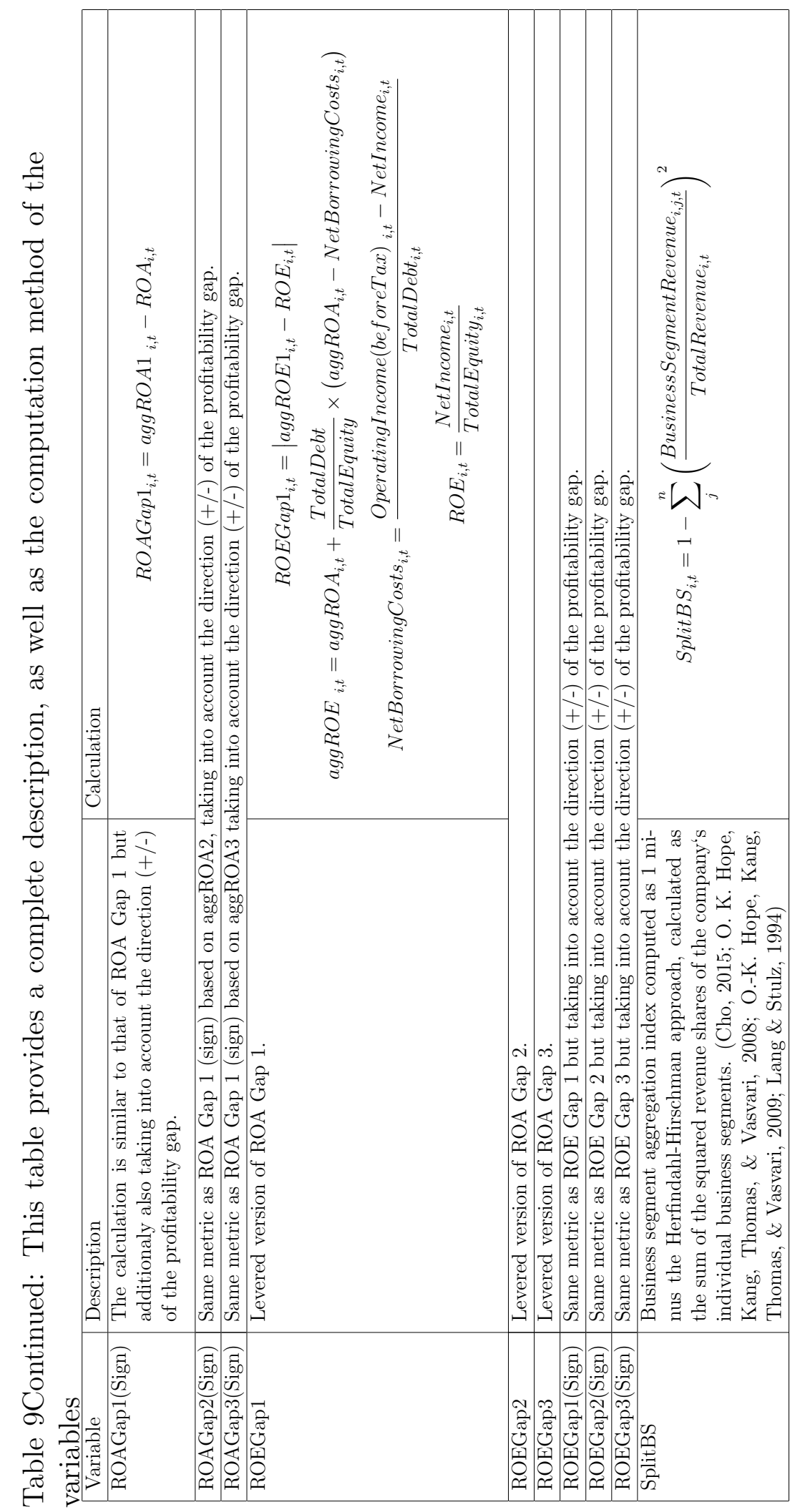




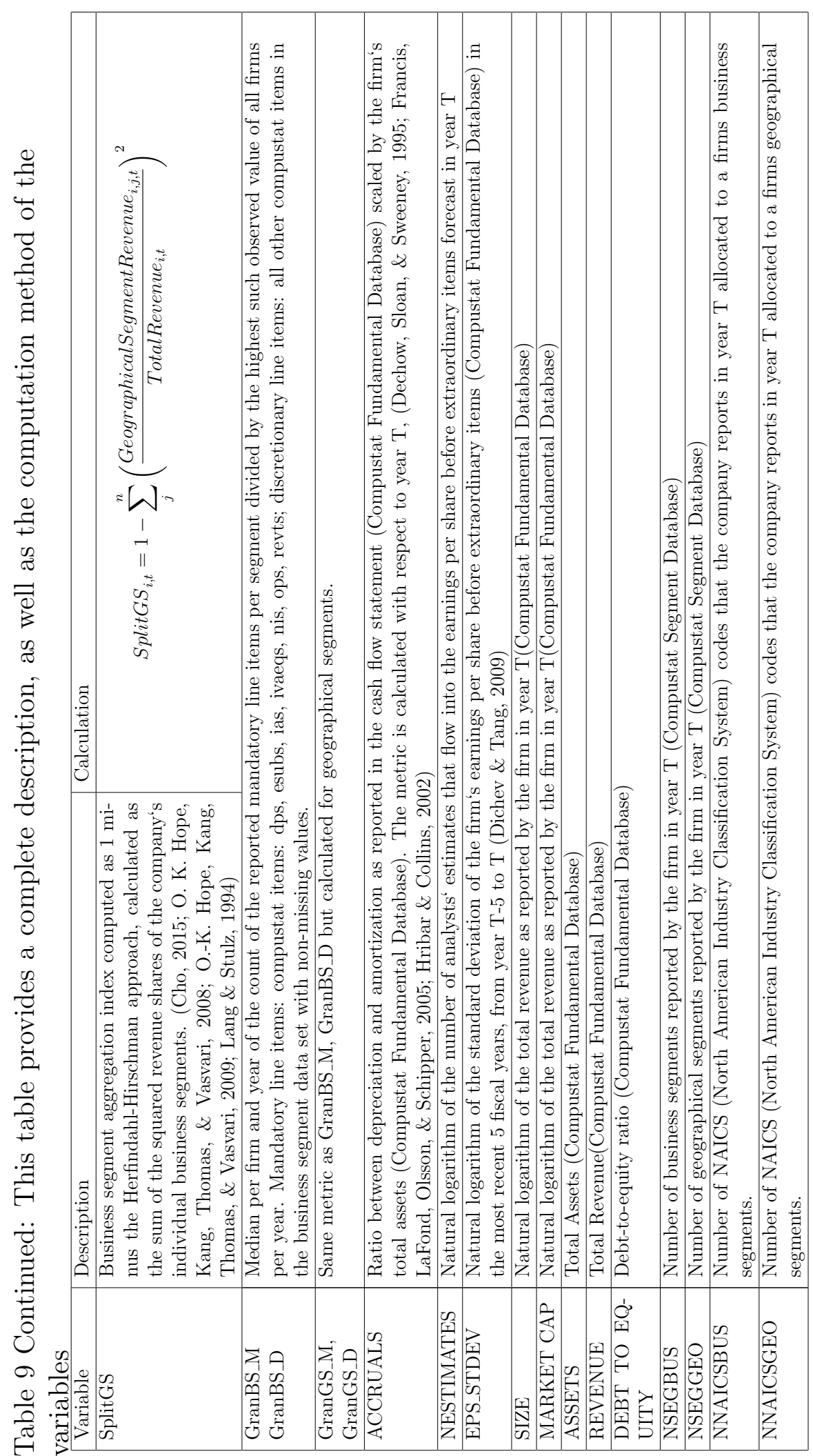

